\title{
The Brown Alga Ascophyllum Nodosum As A Nutraceutical Useful for the Control of Type II Diabetes
}

\author{
Daniela Gabbia*, Maria Carrara and Sara De Martin \\ Department of Pharmaceutical and Pharmacological Sciences, University of Padova, Italy
}

Submission: June 20, 2018; Published: August 24, 2018

*Corresponding author: Daniela Gabbia, Department of Pharmaceutical and Pharmacological Sciences, University of Padova, 35131 Padova, Italy; Tel: +39-049-827-5104; Fax: +39-049-827-5093; Email: daniela.gabbia@unipd.it

\begin{abstract}
In the last few decades, diabetes has become a global health concern, due to its increasing prevalence in developed and developing countries. The most common form of diabetes is type 2 diabetes (T2D), characterized by an impairment of insulin in activating glucose transport system into the cells and an inappropriate hyper-insulinemia due to insulin resistance. The maintenance of normal blood glucose levels is one of the major goals in diabetes management and could be achieved by reducing the glycemic index (GI) of foods. The brown seaweed Ascophyllum nodosum is an easily available food traditionally used by coastal communities. A. nodosum contains numerous bioactive compounds with several health benefits for humans, i.e. the carotenoid fucoxanthin, phlorotannins, high molecular weight phenolics and simple phenolics, such as catechins, hydroxybenzoic acid, coumaric acid, cinnamic acid, and caffeic acid, all displaying anti-obesity, antidiabetic and antioxidant potential. The reduction and the delay of glucose absorption consequent to the inhibition of the digestive enzymes $\alpha$-glucosidase and $\alpha$-amylase induced by $A$. nodosum can significantly lower postprandial glucose levels by slowing the digestion of dietary starch, the major dietary source of glucose, and decreasing the rate of blood sugar absorption from small intestine. In conclusion, A. nodosum extracts could be administered before a meal to slow down the rate of carbohydrate digestion and assimilation and modulate the glycemic response to high glycemic index (GI) foods. This can help the management of T2D patients and could be use even in synergistic way with other pharmacological treatments.
\end{abstract}

Keywords: Ascophyllum nodosum; Brown seaweed; $\alpha$-Amylase; $\alpha$-Glucosidase; Type 2 diabetes; Antidiabetic effect

Abbreviations: GI: glycemic index; T2DM: Type 2 Diabetes; NASH: Non-Alcoholic Steatohepatitis

\section{Introduction}

Diabetes is nowadays becoming a global health concern due to its increasing prevalence both in developed and developing countries [1]. In 2011, it has been estimated that 347 million adults were affected by diabetes mellitus with an expected increase by $50 \%$ in the next 20 years [2]. The most common type of diabetes is type 2 diabetes (T2D), a metabolic disorder of the endocrine system that could be described as the incapability of insulin to activate the glucose transport system into the cells and an inappropriate hyperinsulinemia, which is due to insulin resistance [3]. As a result, this uncontrolled chronic hyperglycemia is responsible for the development of several vascular complications, such as retinopathy, angiopathy, nephropathy, and neuropathy [3]. There is a general consensus that the maintenance of normal blood glucose levels is one of the major goals in diabetes, and this can be achieved either by stimulating insulin secretion through drug therapy or by means of dietary control [4-6]. The latter approach seems to be a safer and complementary treatment for T2D patients. One of the most recommended nutritional treatments for T2D is based on the reduction of the glycemic index (GI) of foods. Moreover, dietary control could be used to obtain a synergistic effect with other pharmacological treatments [7-9]. The inhibition of carbohydrate digestive enzymes, such as $\alpha$-amylase and $\alpha$-glucosidase, represents an efficient strategy for the dietary control of T2D [5]. Indeed, it has been demonstrated that the inhibition of these digestive enzymes can significantly lower the postprandial glucose level by slowing digestion of dietary starch, the major dietary source of glucose, and decreasing the rate of blood sugar absorption from the small intestine [5]. In T2D patients, this approach seems to be more efficient than controlling insulin secretion, by the fact that it is economic, convenient, and with virtually no adverse reactions [4].

Since the majority of T2D patients under oral hypoglycemic therapy have hyperglycemia due to poor adherence to therapy 


\section{Current Research in Diabetes \& Obesity Journal}

because of the side effects [10], there is a growing interest in the use of natural products with anti-diabetes activity [11]. Brown seaweeds, e.g. Ascophyllum nodosum, are easily available food traditionally used by coastal communities, especially in Asiatic countries [12]. Ascophyllum nodosum is a brown seaweed species belonging to the class of Phaeophyceae, which is commonly growing on the northeastern coast of North America and the northwestern coast of Europe [13]. It has been reported that $A$. nodosum contains several bioactive compounds with numerous health benefits for humans, in particular the carotenoid fucoxanthin [14,15], phlorotannins [16], both high molecular weight- and simple phenolics, like catechins [17], hydroxybenzoic acid, coumaric acid, cinnamic acid, and caffeic acid (Olivier Dumay et al. 2004). These bioactive compounds have anti-obesity, antidiabetic and antioxidant potential [14,18-21]. Moreover, brown seaweed extracts contain sulfated polysaccharides, called fucoidans [22], that have been demonstrated to display multiple pharmacological properties, such as anti-proliferative and anti-inflammatory activities, and help to slowdown food digestion, since they increase viscosity, thus decreasing the absorption of blood sugar and cholesterol [23-25]. Zhang and collaborators have demonstrated that the solvent extracts of $A$. nodosum have a high phenolic content, and their administration could be correlated with a reduction of blood glucose levels in rats [18]. Although in this study, ethanol, butanol, methanol, and acetic acid have been used as solvents to extract active compounds from this seaweed, a water-based extraction system would be more desirable for functional food application, because of the absence of solvent residues [13], as suggested by Apostolidis et al., who studied water extracts obtained from $A$. nodosum demonstrating that they have a significant inhibitory effect on carbohydrate digestive enzymes, which appeared correlated to their phenolic content [26].

Two of the key digestive enzymes involved in starch breakdown and absorption are $\alpha$-amylase and $\alpha$-glucosidase. $\alpha$-amylase is a calcium metalloenzyme, secreted from pancreas and salivary glands, that catalyzes the hydrolysis of the $\alpha$-D-1,4 glycosidic linkages of starch, amylopectin, amylose, glycogen, and many maltodextrins into shorter oligosaccharides. $\alpha$-glucosidase is responsible for the final step of the carbohydrate digestive process in the brush-border surface membrane of intestinal cells, catalyzing the hydrolysis of $\alpha-1,4$ linkage of complex carbohydrates and disaccharides and giving as final products absorbable monosaccharides, e.g. glucose. Kim and collaborators demonstrated that fucoidans extract obtained from $A$. nodosum were able to inhibit both $\alpha$-amylase and $\alpha$-glucosidase, but the concentration of the bioactive compounds required for $\alpha$-amylase inhibition were higher than those for $\alpha$-glucosidase inhibition [27]. Moreover, they speculated the presence of a correlation between the harvesting period of $A$. nodosum and the activity of the algal extracts on carbohydrate hydrolyzing enzymes. As a conclusion, they postulate that the best harvesting periods to obtain the highest $\alpha$-amylase inhibition were summer and autumn, whereas the best harvesting period for $\alpha$-glucosidase inhibition was autumn [27].

The reduction and the delay of glucose absorption through the inhibition of digestive enzymes $\alpha$-glucosidase and $\alpha$-amylase induced by algal extracts obtained from Ascophyllum nodosum had already been demonstrated by several preclinical and clinical studies [13, 28-31]. In particular, Gabbia and collaborators have recently studied the inhibition of digestive enzymes in mice fed with a diet particularly rich in fat, which developed non-alcoholic steatohepatitis (NASH). They found that the administration of a phytocomplex obtained from both Ascophyllum nodosum and Fucus vesiculosus, which is another brown seaweed, caused both a delay in carbohydrate digestion and a significant decrease in their assimilation in these mice [28]. Moreover, these authors suggested that since NASH could be associated with T2D and insulin resistance, brown seaweed extracts may be useful for glycemic control and for prevention of the transition of NASH to T2D.

\section{Discussion and Conclusion}

Ascophyllum nodosum, a seaweed found in abundance along the US Northeast coast, is currently considered one of the underutilized brown algal species that contains a wide range of bioactive compounds with different biological effects [13]. In particular, A. nodosum extracts contain fucoxanthins, catechins hydroxybenzoic acid, coumaric acid, cinnamic acid, and caffeic acid and sulfated polysaccharides, called fucoidans. Among all the beneficial activity of brown algae reported in literature, these bioactive compounds have anti-obesity and antidiabetic potential [14,18-21]. Some studies reported that an efficient strategy to control hyperinsulinemia in T2D patient is the inhibition of carbohydrate digestive enzymes, $\alpha$-amylase and $\alpha$-glucosidase $[4,5]$. Kim and collaborators reported that fucoidans from $A$. nodosum inhibited both enzymes, whereas that obtained from another brown alga, Fucus vesiculosus, inhibited only $\alpha$-glucosidase [22]. Since it has been reported that fiber consumption is related to a significant reduction of multiple chronic diseases, such as diabetes, obesity, and hypertension, fucoidans of Ascophyllum nodosum could represent a pharmacological potential for T2D patients [32].

In conclusion, the pre-prandial administration of $A$. nodosum extracts to T2D patients can be exploited as a strategy to slow down the rate of carbohydrate digestion and assimilation [33]. Thus, the glycemic response to high glycemic index (GI) foods, associated with high blood glucose and insulin resistance, could be modulated by these products into one typical of foods with lower GI [34]. This takes on importance in the management of T2D patients and could be even use in synergistic way with other pharmacological treatments, improving their efficacy.

\section{References}

1. Marín-Peñalver, Juan José, Iciar Martín-Timón, Francisco Javier del Cañizo-Gómez (2016) "Management of Hospitalized Type 2 Diabetes 


\section{Current Research in Diabetes \& Obesity Journal}

Mellitus Patients." Journal of Translational Internal Medicine 4(4): 155-161.

2. Rains, Justin L, Sushil K Jain (2011) “Oxidative Stress, Insulin Signaling, and Diabetes." Free Radical Biology \& Medicine 50(5): 567-575.

3. Chawla A, Chawla R, Jaggi S (2016) Microvasular and macrovascular complications in diabetes mellitus: distinct or continuum? Indian Journal of Endocrinology and Metabolism 20(4): 546-551.

4. Porte D (2001) Clinical Importance of Insulin Secretion and Its Interaction with Insulin Resistance in the Treatment of Type 2 Diabetes Mellitus and Its Complications. Diabetes/Metabolism Research and Reviews 17(3): 181-188.

5. Rabasa-Lhoret, Rémi, Jean-Louis Chiasson (2004) $\alpha$-Glucosidase Inhibitors. In International Textbook of Diabetes Mellitus. John Wiley \& Sons, USA.

6. Goldberg RB, Einhorn D, Lucas CP, Rendell MS, Damsbo P, et al. (1998) A Randomized Placebo-Controlled Trial of Repaglinide in the Treatment of Type 2 Diabetes. Diabetes Care 21(11): 1897-1903.

7. Gannon MC, Nuttall JA, Damberg G, V Gupta, FQ Nuttall (2001) Effect of protein ingestion on the glucose appearance rate in people with type 2 diabetes. Journal of Clinical Endocrinology and Metabolism 86(3): 1040-1047.

8. Jenkins DJ, Wolever TM, Taylor RH, Barker H, Fielden H, et al. (1981) Glycemic Index of Foods: A Physiological Basis for Carbohydrate Exchange. The American Journal of Clinical Nutrition 34(3): 362-366.

9. Wolever, Thomas MSS, Lisa Katzman-Relle, Alexandra L Jenkins, Vladimir Vuksan, et al. (1994) Glycaemic Index of 102 Complex Carbohydrate Foods in Patients with Diabetes. Nutrition Research 14(5): 651-669.

10. Chaudhury A, Chitharanjan D, Vijaya Sena RD, Shashank K, Aditya C, et al. (2017) Clinical Review of Antidiabetic Drugs: Implications for Type 2 Diabetes Mellitus Management. Frontiers in Endocrinology 8: 6.

11. Li WL, Zheng HC, Bukuru J, N De Kimpe (2004) Natural Medicines Used in the Traditional Chinese Medical System for Therapy of Diabetes Mellitus. Journal of Ethnopharmacology 92(1): 1-21.

12. Ruperez P, Ahrazem O, Leal JA (2002) Potential Antioxidant Capacity of Sulfated Polysaccharides from the Edible Marine Brown Seaweed Fucus Vesiculosus. Journal of Agricultural and Food Chemistry 50(4): 840-845.

13. Apostolidis E, Lee CM (2010) In vitro Potential of Ascophyllum nodosum phenolic antioxidant-mediated $\alpha$-glucosidase and $\alpha$-amylase inhibition. J Food Sci 75(3): H97-H102.

14. Yan X, Chuda Y, Suzuki M, Nagata T (1999) Fucoxanthin as the major antioxidant in hijikia fusiformis, a common edible seaweed. Biosci Biotechnol Biochem 63(3): 605-607.

15. Marais MF, Joseleau JP (2001) A Fucoidan Fraction from Ascophyllum nodosum. Carbohydrate Research 336(2): 155-159.

16. Nwosu Felix, Jennifer Morris, Victoria A Lund, Derek Stewart, et al. (2011) Anti-Proliferative and Potential Anti-Diabetic Effects of Phenolic-Rich Extracts from Edible Marine Algae. Food Chemistry 126(3): 1006-1012.

17. Yoshie Y, Wei W, David P, Takeshi S (2000) Distribution of catechins in Japanese seaweeds. Fisheries Science 66(5): 998-1000.

18. Zhang J, Tiller C, Shen J, Wang C, Girouard GS, et al. (2007) Antidiabetic properties of polysaccharide- and polyphenolic-enriched fractions from the brown seaweed Ascophyllum nodosum. Can J Physiol Pharmacol 85(11): 1116-1123.

19. Maeda, Hayato, Masashi Hosokawa, Tokutake Sashima, Nobuyuk Takahashi, et al. (2006) Fucoxanthin and Its Metabolite, Fucoxanthinol,
Suppress Adipocyte Differentiation in 3T3-L1 Cells. International Journal of Molecular Medicine 18(1): 147-152.

20.Xiaojun Yan, Li Xiancui, Zhou Chengxu, Fan Xiao (1996) Prevention of Fish Oil Rancidity by Phlorotannins from Sargassum Kjellmanianum. Journal of Applied Phycology 8: 201-203.

21. Kwon YI, Dhiraj A Vattem, Kalidas Shetty (2006) Evaluation of Clonal Herbs of Lamiaceae Species for Management of Diabetes and Hypertension. Asia Pacific Journal of Clinical Nutrition 15(1): 107-118.

22. Kim KT, Rioux LE, Turgeon SL (2015) Molecular Weight and Sulfate Content Modulate the Inhibition of $\alpha$-Amylase by Fucoidan Relevant for Type 2 Diabetes Management. Innovations and Use of Natural Health Ingredients for Improving Nutrition and Preventing Disease 3(3): 108-114.

23. Mabeau SB Kloareg, Joseleau JP (1990) Fractionation and Analysis of Fucans from Brown Algae. Phytochemistry 29(8): 2441-2445.

24. Landin KG, Holm L, Tengborn, Smith U (1992) Guar Gum Improves Insulin Sensitivity, Blood Lipids, Blood Pressure, and Fibrinolysis in Healthy Men. American Journal of Clinical Nutrition 56(6): 1061-1065.

25. Ou Shiyi, Kin-chor Kwok, Yan Li, Liang Fu (2001) In Vitro Study of Possible Role of Dietary Fiber in Lowering Postprandial Serum Glucose. J Agric Food Chem 49(2): 1026-1029.

26. Apostolidis E, Karayannakidis PD, Young In IK, Chong ML, Navindra PS (2011) Seasonal variation of phenolic antioxidant-mediated $\alpha$-glucosidase inhibition of Ascophyllum nodosum. Plant Foods for Human Nutrition 66(4): 313-319.

27. Kim KT, Rioux LE, Turgeon SL (2014) Alpha-Amylase and AlphaGlucosidase Inhibition Is Differentially Modulated by Fucoidan Obtained from Fucus Vesiculosus and Ascophyllum nodosum. Phytochemistry 98: 27-33.

28. Gabbia D, Dall'Acqua S, Di Gangi IM, Bogialli S, Caputi V, et al. (2017) The Phytocomplex from fucus vesiculosus and Ascophyllum nodosum controls postprandial plasma glucose levels: an in Vitro and in Vivo study in a mouse model of NASH. Marine Drugs 15(2): 41.

29. Etxeberria U, de la Garza AL, Campión J, Martínez J Alfredo, Milagro Fermín I (2012) Antidiabetic effects of natural plant extracts via inhibition of carbohydrate hydrolysis enzymes with emphasis on pancreatic alpha amylase. Expert Opinion on Therapeutic Targets 16(3): 269-297.

30. Paradis ME, Couture P, Lamarche B (2011) A Randomised Crossover Placebo-Controlled Trial Investigating the Effect of Brown Seaweed (Ascophyllum Nodosum and Fucus Vesiculosus) on Postchallenge Plasma Glucose and Insulin Levels in Men and Women. Applied Physiology, Nutrition, and Metabolism 36(6): 913-919.

31. Terpend, Kathleen, Jean François Bisson, Claire Le Gall, Elodie Linares (2012) Effects of ID-AlGTM on Weight Management and Body Fat Mass in High-Fat-Fed Rats. Phytotherapy Research 26(5): 727-733.

32. Hall AC, Fairclough AC, Mahadevan K, Paxman JR (2012) Ascophyllum Nodosum Enriched Bread Reduces Subsequent Energy Intake with No Effect on Post-Prandial Glucose and Cholesterol in Healthy, Overweight Males. A Pilot Study. Appetite 58(1): 379-386.

33. Cade W Todd (2008) Diabetes-related microvascular and macrovascular diseases in the physical therapy setting. Physical Therapy 88(11): 1322-1335.

34. Dumay 0, Costa J, Desjobert JM, Pergent G (2004) Variations in the Concentration of Phenolic Compounds in the Seagrass Posidonia Oceanica under Conditions of Competition. Phytochemistry 65(24): 3211-3220. 
(C) This work is licensed under Creative BY DOI: 10.19080/CRDOJ.2018.08.555741

\section{Your next submission with Juniper Publishers} will reach you the below assets

- Quality Editorial service

- Swift Peer Review

- Reprints availability

- E-prints Service

- Manuscript Podcast for convenient understanding

- Global attainment for your research

- Manuscript accessibility in different formats

( Pdf, E-pub, Full Text, Audio)

- Unceasing customer service

Track the below URL for one-step submission

https://juniperpublishers.com/online-submission.php 